\title{
Discussion of the Influence Mechanism of Psychological Environment in Classroom for Effective Teaching
}

\author{
Min Xu \\ School of Education Science, Nanjing Normal University, Nanjing, China \\ Email: jmwillin@163.com
}

Received 8 July 2015; accepted 15 August 2015; published 19 August 2015

Copyright (C) 2015 by author and Scientific Research Publishing Inc.

This work is licensed under the Creative Commons Attribution International License (CC BY). http://creativecommons.org/licenses/by/4.0/

(c) () Open Access

\begin{abstract}
Psychological environment in classroom is the sum of various potential environmental factors with the actual impact in classroom teaching, which has a substantial influence on effective teaching. This paper explores the influence mechanism of psychological environment in classroom for effective teaching mainly from psychological field, distributed cognition theory, situational learning theory and on embodied cognition as well as how to create psychological environment in classroom to achieve effective teaching.
\end{abstract}

\section{Keywords}

Psychological Environment in Classroom, Effective Teaching, Influence Mechanism, Constructional Path

\section{Introduction}

Effective teaching has become a hot research in recent years, which is defined by most scholars as effective, efficient and cost-effective teaching (Chen, 2012). There are many factors having impacts on effective teaching, but previous studies mainly focus on teachers and students' inner psychological factors. Now, as people gradually pay attention to material impacts on effective teaching from classroom environment, the research focus has switched to the overall background of teaching. In order to promote effective teaching, it's necessary to study classroom environment, at the same time, the research on the physical environment is abundant, but relatively few studies about psychological environment. So, this paper mainly explores why classroom psychological environment affects effective teaching, namely of influence mechanism, as well as how to create classroom psychological environment to promote effective teaching, namely of constructional path. 


\section{The Impact Mechanism of Psychological Environment in Classroom for Effective Teaching}

Classroom psychological environment means the sum of various potential environmental factors with the actual impact in classroom teaching, which mainly consists of classroom psychological atmosphere, interpersonal relationship, students' psychological factors and collective norms. The impact mechanism is as follows:

\subsection{Psychological Field Theory}

Psychological field theory was put forward by Lewin in the 1930s, who thought that people are a complex energy system and there is a psychological living space (LSP) including E (psychological environment composed by the facts of quasi-physical, quasi-social, and quasi-concept) and P (people whose internal personal area composed by needs, desires, and intentions for consciousness movement area) (Liu, 1998). Any behavior of people is in the psychological living space. Hereby, Lewin put forward a famous formula: $B=f(P E)=f(L S)$ ( $B$-behavior, $F$-function relationship, $E$-environment, $L S$-living space), namely, individual behavior is not only the function of people and environment, but also the living space (Ma, 2003).

Based on the theory of psychological field, as the main bilateral subjects in teaching, teachers and students' behaviors must be influenced by classroom psychological environment, which are the results of the interaction between individual and environment, and depended by the whole psychological living space. Hence, in order to promote positive behaviors and enhance effective teaching, we must pay attention to the profound relationship between the psychological environment and individual's behavior, and create the best psychological environment to make sure optimum situation of teaching behavior, making teaching to optimize.

\subsection{Distributed Cognition Theory}

The concept of distributed cognition was put forward by Hutchins in the mid-1980s (Rogers, 1997), which means cognition not only exists in people's inner, but also distributes between the individuals, media, environment, society, culture and time (Cole \& Engestrom, 1993). It's the integrate system consisting of cognitive subjects and all the things involved in cognition. The system's core is the individual cognition, existing in the environment and interacting with the environment all the time.

Hutchins thought that individual cognition must be shared through interaction with others, especially in the situation, as a consequence, it can get development. So distributed cognition theory has the concept of "learning community". When students communicate with each other face to face, the culture of community can pose potential impact on them. Distributed cognition emphasizes the profound influence of environment on individual cognitive activities, as Simon said “Ant's complex path of movement on the beach is caused by the beach, rather than its own” (Jonassen, 2012). Environment provides the background of interaction, collaboration, reflection and improvement for individual learning, only in which, it's possible to discuss the development of individual cognitive. Students' cognitive development is one of the important goals of classroom teaching, and also the key to test the effective teaching. Likewise, the points of view from distributed cognition theory illustrate the impacts of environment on students' learning. Briefly, we can say that environment by influencing the individual's cognition further influences effective teaching; the same is true of classroom psychological environment.

\subsection{Situational Learning Theory}

Situational learning theory entered the research field of human learning in 1990s, gradually becoming a new research paradigm. It can be divided into two research orientations: psychology and anthropology (Jia \& Han, 2011). Situational learning theory’s core concept is “Legitimate peripheral participation”, meaning the progress that a novice gradually becomes a specialist in practice community. In teaching, students are trying to turn into the core member in community (Lave \& Wenger, 1991), therefore, the norms of community can have an influence on them. So, students will act consciously in accordance with the standards of the community, which can help teachers to manage the class.

In the same way, situational learning theory emphasize that learning is the result of the interaction between individual and environment, from which students select or determine their own behavior, thus teachers must strive to set consistent situation so as to match the real situation, making students build their own knowledge structure on this basis. From the situational learning theory, we can learn the influence of environment on 
teaching is so great that it not only restricts communication between teachers and students, but also involves students' level of compliance with collective specifications. The good or bad of situation's creation even decides whether classroom atmosphere lively and vivid, and these are the elements of classroom psychological environment, which all affect effective teaching.

\subsection{On Embodied Cognition Theory}

The main point of on embodied cognition theory is that cognition occurs in people's body, and the body exists in the situation, so once the body out of the situation, cognition will be out of the question and become offline cognition, In conclusion, cognition has the characteristics of situation (Wilson, 2002).

A basic proposition of on embodied cognition theory is that body plays an important role in the development of cognition, and the interaction between body and environment determines the nature and reaction mode of cognition, etc. Only through this kind of interaction, students' cognition will be personalized, unique and profound. In teaching, teacher should make students be in a state of relaxation so that students' mood isn't too nervous, on the contrary, it can do good to the efficiency of listening to lectures. If students' body has always been in a state of bondage, their mentality naturally won't feel at ease. Consequently, teachers should learn to achieve the best state of mind and body between each other in a good situation and harmonious dialogue with students.

From on embodied cognition theory, classroom psychological environment firstly has an effect on students' body, for instance, mood-relaxed classroom psychological atmosphere and harmonious interpersonal relationships etc can make students' body comfortable, then influences the elimination of anxiety, improvement of confidence, acquisition of knowledge and skills, subsequently the growth of cognition. Ultimately classroom psychological environment raises the level of effective teaching.

\section{The Constructional Path of Psychological Environment in Classroom}

Although classroom psychological environment is decided by many factors, teachers are the key factor of its creation. Thus, this paper mainly analyzes the constructional path from the perspective of teachers, describing how a teacher should do to establish good psychological environment in classroom for students so as to achieve effective teaching.

\subsection{Teacher's Accomplishment}

Teacher's accomplishment is the premise to create good classroom psychological atmosphere, when creating classroom psychological environment, teachers should firstly find approaches from their own, but what qualities should be concerned about by teachers? The result of a survey from Chinese Academy of Social Sciences in Sichuan province showed that in the eyes of students from middle and high school, most popular qualities of teachers are sense of responsibility and initiative, fair, care, respect, democracy, vivid teaching etc. (Zha, 1989).

From author's point of view, teachers' emotional quality is one of the most important accomplishments. It has a remarkable influence when creating classroom psychological atmosphere, so it's also an effective breakthrough point in the construction of classroom psychological environment. Teachers' emotion is an important part of teachers' teaching charm, which often does not only refer to personal feelings of teachers, in fact, it's a collective mood combined with students' emotion in teaching, full of generativity and richness. Cognitive psychology thinks when teaching is in positive emotional environment it can effectively promote the implementation of cognitive strategies. Therefore, teachers should control their negative feelings in class, and use pleasant emotions to infect each student. Particularly when meeting unexpected situations in classroom, teachers must keep calm and improve teaching wit, striving to deal with the problem in the shortest time.

\subsection{Teacher-Student Relationship}

Interpersonal relationship as the main factor in classroom psychological environment, especially teacher-student relationship, is the key in the construction of classroom psychological environment. In the new teacher-student relationship, teachers should take the initiative to realize the role transition, from a strict teacher imparting knowledge to a spiritual teacher filled with wisdom, and pay enough emphasis on equal dialogue with students.

When it comes to "dialogue", teachers must convert from one-way infusion into friendly interactions with 
students, and encourage students to ask question, thereby teachers and students can get progress in the dialectical thinking and achieve the teaching goal in the good interaction. Teachers should be able to utilize questions to promote learning in the dialogue, encourage different views and grasp the essence of appreciation education. As a result, teachers can truly become students' learning motivation and role models.

\subsection{Physical Environment}

Classroom physical environment is closely linked to psychological environment, and its arrangement will affect individual psychological factors, for instance, classroom lighting and ventilation can impact students' visual and auditory function; the clean and tidy of classroom can also affect students' mood. But this paper mainly emphasizes classroom seat model in physical environment.

In class teaching system, the classroom seats are mainly placed in the form of seedling bed. When teacher stands on the platform, the platform has become the pressure source of students. The first few rows of students are located in the high pressure zone, middle rows of students are in medium pressure zone, while students in back rows are in powder press section (Tian, 1993). If students are in the high and middle pressure zone, they will get more attention from teachers, so they can be regulated effectively. But if they were always in this condition, they would easily generate psychological anxiety, which can be bad for high-intensity learning tasks. While students in powder press section who are far away from the platform are easily vulnerable to be alienated, they are relatively slack and can become weak zone of classroom management.

Hence, teachers need to understand the advantages and disadvantages of different seat models, and adjust the seating arrangements flexibly according to the class type. For example, seminar class may adopt horseshoe type, in order to facilitate multi-directional communication of information.

\subsection{Class Atmosphere}

Teacher is the key to promote the formation of good class atmosphere, when constructing the class atmosphere, teachers should notice two important points: one is making students learn to learn, the other is making the class willing to learn.

Teachers ought to guide students learning methods and teach them to focus on the accumulation of learning methods, which can achieve "Yield twice the result with half the effort" and "Teaching is for the sake of no needing teaching". The nature of "Willing to learn" is to mobilize the learning enthusiasm of students and promote active teaching process (Li, 2003), so “Willing to learn” in the class can not only improve students' learning interest, but also help to cultivate creative thinking. Therefore, teachers should use entertaining teaching methods more than before, making students enjoy happy emotional experience in the classroom, generating curiosity for knowledge and developing the potential.

Besides, teachers also need to focus on the cooperation between students, increase group discussion and practice training appropriately as well as promote the communication of learning experience and methods between students, which will undoubtedly play a catalytic role on the construction of class atmosphere and formation of collective norms.

\section{Conclusion}

After analyzing the influence mechanism of psychological field, distributed cognition theory, situational learning theory and on embodied cognition, classroom psychological environment firstly by influencing teachers and students' behavior or cognition further promotes effective teaching, as well as by influencing the classroom atmosphere or students' body then achieves effective teaching. In short, the study of classroom psychological environment can provide a scientific guidance for teachers in the actual process of creating. It can also alter the phenomenon that in the past, people only paid attention to the physical environment but ignored the psychological environment. When teachers and students are in a cycle of "perception-action" with the classroom psychological environment, students will enter the state of deep learning, thus, teachers naturally become students' learning facilitators.

\section{References}

Chen, Y. Q. (2012). Discussions on the Analysis Model for Effective Teaching. Curriculum Teaching Material and Method, 
11, 3-9.

Cole, M., \& Engestrom, Y. (1993). A Cultural-Historical Approach to Distributed Cognition.

Jia, Y. Z., \& Han, C. Q. (2011). Situated Learning: A New Research Paradigm on Learning. Open Education Research, 5, 29-31.

Jonassen, D. H. (2012). Theoretical Foundations of Learning Environments (2nd Revised ed.). London: Routledge.

Lave, J., \& Wenger, E. (1991). Situated Learning: Legitimate Peripheral Participation. Cambridge, UK: Cambridge University Press. http://dx.doi.org/10.1017/CBO9780511815355

Li, R. M. (2003). Research on Modern Teaching Theory. Changchun, Jilin: Jilin People’s Publishing House.

Liu, H. Y. (1998). Review of Lewin’s Social Psychology Theory. Social Psychological Science, 1, 59.

Ma, Xinchuan. (2003). Modern Psychology Theories (pp. 173-177). Shanghai: East China Normal University Press.

Rogers, Y. (1997) A Brief Introduction to Distributed Cognition. http://www.cogs.susx.ac.uk/users/yvonner/dcog.html

Tian, H. S. (1993). The Potential Impact of Teaching Environment on Students Learning Activities. Curriculum Teaching Material and Method, 10, 32.

Wilson, M. (2002). Six Views of Embodied Cognition. Psychonomic Bulletin \& Review, 4. http://dx.doi.org/10.3758/BF03196322

Zha, Y. L. (1989). The Poll of Education Quality. Higher Normal Education Research, 4, 52-53. 